\title{
Microspherical Particles of Solid Dispersion of Polyvinylpyrrolidone K29-32 for Inhalation Administration
}

\author{
L. S. Usmanova, ${ }^{1}$ M. A. Ziganshin, ${ }^{1}$ I. T. Rakipov, ${ }^{1}$ N. M. Lyadov $\mathbb{D}^{1,3},{ }^{2,3}$ A. E. Klimovitskii, ${ }^{1}$ \\ T. A. Mukhametzyanov, ${ }^{1}$ and A. V. Gerasimov $\mathbb{B}^{1}$ \\ ${ }^{1}$ Department of Physical Chemistry, A.M. Butlerov Institute of Chemistry, Kazan Federal University, Kremlevskaya 18, \\ Kazan 420008, Russia \\ ${ }^{2}$ ZPTI-Subdivision, FIC KazanSC of RAS, Sibirsky Tract 10/7, Kazan 420029, Russia \\ ${ }^{3}$ Institute of Engineering, Kazan Federal University, Kremlevskaya 18, Kazan 420008, Russia
}

Correspondence should be addressed to A. V. Gerasimov; alexander.gerasimov@kpfu.ru

Received 15 August 2017; Revised 11 November 2017; Accepted 23 November 2017; Published 10 January 2018

Academic Editor: Sami M. Nazzal

Copyright (C) 2018 L. S. Usmanova et al. This is an open access article distributed under the Creative Commons Attribution License, which permits unrestricted use, distribution, and reproduction in any medium, provided the original work is properly cited.

\begin{abstract}
Inhalation administration is a promising alternative to the invasive drug delivery methods. The particle size required for ideal drug aerosol preparation is between 1 and $3 \mu \mathrm{m}$. The application of microspherical particles of solid dispersions enhances bioavailability of poorly soluble drugs due to the solubilization. In the present work, the spray drying process of the production of microspherical particles of solid dispersions of polyvinylpyrrolidone K29-32 with model hydrophobic drug, phenacetin, was optimized using the results of DSC, PXRD, and viscometry. The diameter of the obtained particles is within 1-3 $\mu \mathrm{m}$ range. The Gibbs energy of dissolution in water was shown to be negative for the mixture with polymer/phenacetin mass ratio $5: 1$. We have demonstrated that the optimal size distribution for the inhalation administration is obtained for microspherical particles produced using spray caps with $7.0 \mu \mathrm{m}$ hole size. The dissolution rates of phenacetin from the produced microspherical particles were faster than that of drug powder. As evidenced by powder X-ray diffraction data, phenacetin stayed in amorphous state for 4 months in microspherical particles of solid dispersions. According to the obtained results, strategic application of the spray drying process could be beneficial for the improvement of the pharmaceutical properties of model drug, phenacetin.
\end{abstract}

\section{Introduction}

Inhalation therapy is an express method of drug delivery into the human circulatory system. Due to extremely abundant capillary network and enormous alveoli area drugs are absorbed extremely rapidly $[1,2]$. The inhaled chemicals are not subjected to the biotransformations, which occur in the digestive tract, and drug activity is not reduced in the liver [3]. Drugs introduced into lungs via inhalation have 10 to 200 times higher bioavailability than by nasal or gastrointestinal administration [4]. Furthermore, inhalation administration of drug compound in an aerosol with controlled particle size and shape may serve as a noninvasive alternative to injection of medicines.

In an inhalation therapy, inhaled drugs enter the body as aerosols. Therapeutically active particle size is limited between 1 and $5 \mu \mathrm{m}$ [5]. Particles with a diameter higher than $10 \mu \mathrm{m}$ are deposited in the oropharynx, those measuring between 5 and $10 \mu \mathrm{m}$ accumulate in the central airways, and those from 0.5 to $5 \mu \mathrm{m}$ enter the small airways and alveoli [6]. In order to target the alveolar region specifically, the aerosol particle diameter should not exceed $3 \mu \mathrm{m}$ [7]. Particles with a diameter below $1 \mu \mathrm{m}$ are exhaled during normal tidal breathing [7]. Moreover, the work [8] demonstrated that particles less than $1 \mu \mathrm{m}$ in size are more readily subjected to phagocytosis. Therefore, the ideal drug aerosol must have particles with a diameter in 1 to $3 \mu \mathrm{m}$ range [2].

On the other hand, most novel drugs are poorly soluble in water limiting their bioavailability $[9,10]$. The most convenient means for "hydrophilization" of drugs is solid dispersion formation [11, 12].

Biocompatible polymers including polyvinylpyrrolidone (PVP) have found wide application as water-soluble matrix for drug delivery $[13,14]$. 
It was earlier demonstrated that PVP produces solid dispersions with a wide range of compounds [15-20] and that a decrease of cytotoxicity of active pharmaceutical ingredients (API) occurs due to solid dispersion formation [21]. The fact that PVP shows protective properties towards macrophage action on compounds encapsulated in the polymer is shown $[22,23]$.

It must be considered that polymers used for solubility increase not only affect pharmacological properties of drugs but also have their own activity profile and toxicity [7, 24, 25]. In this respect, PVP is among most promising materials as its biocompatibility and its usage as plasma replacement illustrate the almost complete lack of toxicity [26-28].

The main problem of solid dispersion production is the determination of the range of polymer : drug composition in which crystalline drug is still not found while the composite is readily soluble in water.

Amorphous glassy state should provide stability towards degrading action of oxygen and humidity due to high viscosity and density. The glass transition temperature is an important parameter controlling the stability of an amorphous state. Therefore, the end product of solid dispersion formation (including spray drying) should has the glass transition temperature significantly higher than room temperature. It must be noted that pharmaceutical substance due to strong intermolecular interactions with polymer matrix may not only act as a plasticizer [29] but also affect the rate of release [30], which further complicates optimization of the polymerdrug ratio.

Presently one of the main methods of nano- and microparticle preparation is the spray drying process, which has found a good use for commercial-scale production for inhaler products. This method enables the production of spherical particles with sharp size distribution [31], as well as solid dispersions of drugs [32]. Furthermore spherical particles demonstrate lower toxic effects than that of other shapes [33], which makes spray drying the most promising method for the preparation of medical products for inhalation administration. Only a limited number of commercially available devices allow production of spherical particles of the $1-3 \mu \mathrm{m}$ size range. The production rate of such devices is usually limited and strongly depends on the viscosity (concentration) of the feeder solution and temperature (feed rate) of the desiccant $[34,35]$. The parameters of the spray drying process also have a significant effect on the morphology of produced particles [36-40].

For example, it is noted [41] that the use of viscous polymer solutions in the spray drying process decreases the yield of target product by $0.5-10 \%$. Furthermore, high hygroscopicity of solution may lead to the formation of particles with broad size distribution due to aggregation during the spray drying process and after that [42]. Particles with broad size distribution cannot be used for inhalation delivery.

Thus the development of the production method of the micrometer-size spherical solid dispersion particles based on polyvinylpyrrolidone via spray drying process as well as optimization of such process is an important current problem of the modern pharmacology.
In the present work, a composition of solid dispersions of polyvinylpyrrolidone K29-32 with well-established model hydrophobic drug compound, phenacetin [43-45], was optimized based on data from a combination of physicochemical methods. The optimal concentration of drug components in solution was found which enables the production of spherical microparticles with a mean diameter in the range between 1 and $3 \mu \mathrm{m}$, suitable for inhalation administration and allowing relatively high dissolution rate. Preliminary minimal set of physicochemical methods required to produce PVP solid dispersions using spray drying process includes (but is not limited to) the following: differential scanning calorimetry and X-ray powder diffraction as well as determination of rheological properties of the solution and quantitative dissolution process investigation.

\section{Materials and Methods}

2.1. Materials. Polyvinylpyrrolidone K29-32 MW 58,000 (PVP K29-32) (Acros Organics, Lot A0357351) and phenacetin, 98\% (PHE) (Aldrich, Lot \#BCBD7322V), were used as received. Absolute ethanol and bidistilled water were used as solvents.

2.2. Preparation of Physical Mixture. Mechanical mixtures of PVP K29-32 with PHE were prepared by mixing measured quantities of substances in an agate mortar until complete homogenization was achieved. Mass ratios of PVP K2932 : PHE were $1: 1,2: 1,3: 1,4: 1,5: 1,6: 1,7: 1,8: 1,9: 1$, and $10: 1$. The resulting mixture was a white powder.

Composites of PHE/polymer were prepared by melting of mechanical mixtures with the required content of components in the ratios 1-10:1 by weight. Melting was carried out under an inert atmosphere at $135^{\circ} \mathrm{C}$ with subsequent cooling down to room temperature.

2.3. Simultaneous Thermogravimetry, Differential Scanning Calorimetry, and Mass-Spectroscopy (TG/DSC/MS). Simultaneous thermogravimetry and differential scanning calorimetry (TG/DSC) analysis of solid samples and mass spectrometric (MS) evolved gas analysis were performed using the thermoanalyzer STA 449F1 Jupiter (Netzsch, Germany) coupled with quadrupolar mass-spectrometer QMS 403 D Aeolos (Netzsch, Germany) at the temperature range of $40-200^{\circ} \mathrm{C}\left(40-500^{\circ} \mathrm{C}\right.$ for initial samples). In each experiment, the temperature scanning rate was $5^{\circ} \mathrm{C} / \mathrm{min}$, and an argon atmosphere with a total flow rate of $75 \mathrm{ml} / \mathrm{min}$ was used [46].

2.4. Differential Scanning Calorimetry (DSC). Enthalpies and transition temperatures of PHE and PVP K29-32, as well as their mechanical mixtures in the temperature range of $-60-160^{\circ} \mathrm{C}\left(-60-200^{\circ} \mathrm{C}\right.$ for PVP K29-32), were determined using differential scanning calorimeter DSC 204 F1 Phoenix (Netzsch, Germany), as described earlier [47, 48]. Measurements were carried out on samples weighing $5.5-12.1 \mathrm{mg}$, at a heating rate of $5^{\circ} \mathrm{C} / \mathrm{min}$ (cooling $10^{\circ} \mathrm{C} / \mathrm{min}$ ), in a dynamic atmosphere of argon $(150 \mathrm{ml} / \mathrm{min})$.

2.5. Powder X-Ray Diffraction. Powder X-ray diffraction (PXRD) studies of polymer, PHE, and their composites were 
made using a MiniFlex 600 diffractometer (Rigaku, Japan) equipped with a D/teX Ultra detector. In this experiment, $\mathrm{Cu}$ $\mathrm{K} \alpha$ radiation $(40 \mathrm{kV}, 15 \mathrm{~mA})$ was used and data were collected at room temperature in the range of $2 \theta$ from 3 to $50^{\circ}$ with a step of $0.02^{\circ}$ and exposure time at each point of $0.24 \mathrm{~s}$ without sample rotation $[46,49]$.

2.6. Limiting Solubility of Phenacetin. UV-spectroscopy (Cary 100 UV-Vis Spectrophotometer (Agilent Technologies, Germany)) was used to determine the effect of PVP K29-32 on limiting solubility of PHE. A series of solutions was prepared with a fixed content of drug $20 \mathrm{mg} / \mathrm{ml}$ at different PVP K29-32:PHE ratios $(1: 1,2: 1,4: 1,6: 1,8: 1$, and $10: 1$ ). After 24 hours, solutions were filtered out from the undissolved part of PHE using a filter of $0.22 \mu \mathrm{m}$ pore diameter. The increase of $\mathrm{PHE}$ content in water at $25^{\circ} \mathrm{C}$ was determined as a ratio of the optical density values at $245 \mathrm{~nm}$ (with suitable dilutions), obtained in the presence of a different quantity of polymer and without it.

Gibbs free energy value $\left(\Delta_{S} G\right)$, related to the process of dissolution of PHE in an aqueous solution of PVP K29-32, was calculated for each concentration of polymer as described previously [50].

2.7. Study of the Viscosity Properties. For optimization of spray drying process, rheological properties of PVP K2932 ethanol solutions were studied. Solutions with PVP K2932 content of $0.05,0.1,0.5,1.0,2.5,3.5$, and $5.0 \% \mathrm{w} / \mathrm{v}$ were prepared to perform the measurements. Viscosity and density assays were carried out using velocity meter DSA 5000 (Anton Paar, Austria) at $20^{\circ} \mathrm{C}, 25^{\circ} \mathrm{C}, 30^{\circ} \mathrm{C}, 35^{\circ} \mathrm{C}, 37^{\circ} \mathrm{C}$, and $40^{\circ} \mathrm{C}$ [51]. The temperature was controlled by a built-in Peltier thermostat within $\pm 0.002^{\circ} \mathrm{C}$.

2.8. Spray Drying. PVP K29-32/PHE solution (2.5\% w/v) was prepared by dissolving $0.8334 \mathrm{~g}$ of PVP K29-32 powder and $0.1666 \mathrm{~g}$ of PHE in $40 \mathrm{ml}$ of ethanol. Solid dispersion particles were prepared by Nano Spray dryer B90 (Buchi, Switzerland) operated in the open mode with three different spray caps (4.0, 5.5, and $7.0 \mu \mathrm{m}$ hole size): flow rate was $7 \mathrm{ml} / \mathrm{min}$; drying air flow $130 \mathrm{l} / \mathrm{min}$; and inlet temperature $65^{\circ} \mathrm{C}$. Dried solid dispersion particles were collected from the particle collecting chamber using a scraper, and the collected powders were kept in Eppendorf type tubes at room temperature (RT).

2.9. Fourier Transformation-Infrared Spectroscopy (FTIR) Analysis of Solid Samples. FTIR spectra $\left(600-4000 \mathrm{~cm}^{-1}\right)$ were acquired for solid samples of pure PVP K29-32, PHE, and their composites. Data were collected using a Vertex 70 FTIR spectrometer (Bruker, Germany) with a single reflection and germanium crystal ATR accessory (MIRacle, PIKE Technologies, USA) purged under dry air to remove atmospheric water vapor. Background spectra of 128 scans at a resolution of $2 \mathrm{~cm}^{-1}$ were subtracted from the sample spectra [50].

2.10. Morphologies of Microparticles. Sample morphology studies were performed on Zeiss EVO 50 XVP scanning electron microscope (Carl Zeiss, Germany) in variable pressure

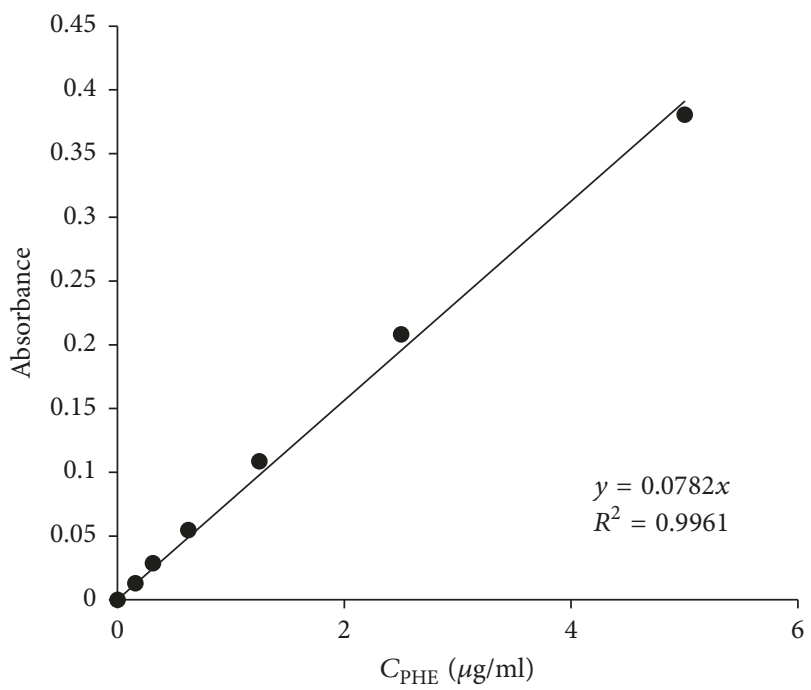

FIGURE 1: Calibration curve for phenacetin concentration in ethanol. Absorbance values are corrected for dilution.

mode. This mode is suitable for nonconducting and gasemitting samples. In the present study, the pressure in the working chamber was 20-30 Pa. For image acquisition, tetrasolid-state BSE detector (reflected electron detector) was used. Samples were visualized using an acceleration voltage of $20.0 \mathrm{kV}$. Image-Pro Plus 6.0.0.260 and Origin 8.1 software packages were used to build distribution curves.

2.11. Drug Contents in Microparticles. The total drug content in the spray-dried particles was assayed by dissolving the solid dispersion in ethanol as described in [52]. The concentration of microparticles in ethanol was $10 \mathrm{mg} / \mathrm{ml}$. The mixture was stirred continuously overnight at RT. Solutions were then analyzed with Cary 100 UV-Vis Spectrophotometer (Agilent Technologies, Germany) at $245 \mathrm{~nm}$ with suitable dilutions. The drug content was calculated using regression equation (Figure 1).

2.12. In Vitro Dissolution. PHE dissolution kinetics from composites was assayed with Dissotest CE1 (Sotax, Switzerland) (USP IV) in a closed loop [53]. Samples containing an equivalent amount of PHE (12.5 mg) were used for dissolution investigation.

The test was performed at $37.0^{\circ} \mathrm{C}$ with $17 \mathrm{ml} / \mathrm{min}$ flow rate, employing phosphate buffer with $\mathrm{pH}=6.86$ as dissolution medium. At different times (after 1, 2, 3, 4, 5, 10, 15, 20, 25, 30, $60,90,120,150$, and 180 minutes) a set solution volume was taken for analysis. Taken volume was replaced with the same amount $(4 \mathrm{ml})$ of fresh medium to replenish solution. PHE content was measured spectrophotometrically using Cary 100 UV-Vis Spectrophotometer (Agilent Technologies, Germany) at $245 \mathrm{~nm}$ with suitable dilutions.

2.13. Statistical Analysis. Statistical analyses were performed using Student's $t$-test or one-way analysis of variance (ANOVA). A $P$ value of $<0.05$ was considered significant for all analyses. All data are expressed as a mean and standard deviation from at least three independent experiments. 


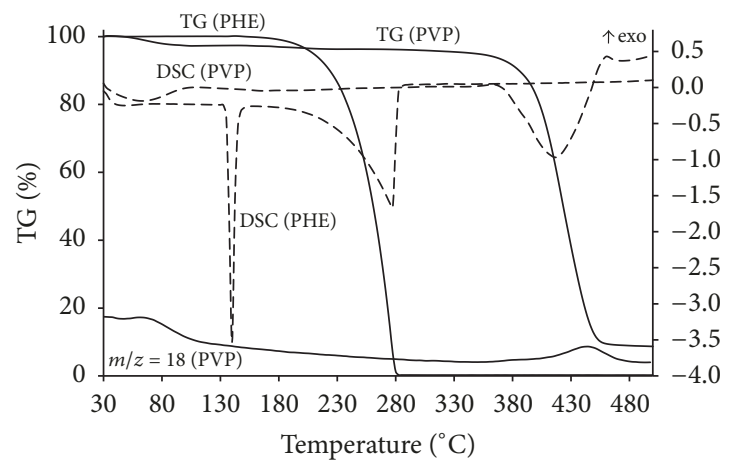

(a)

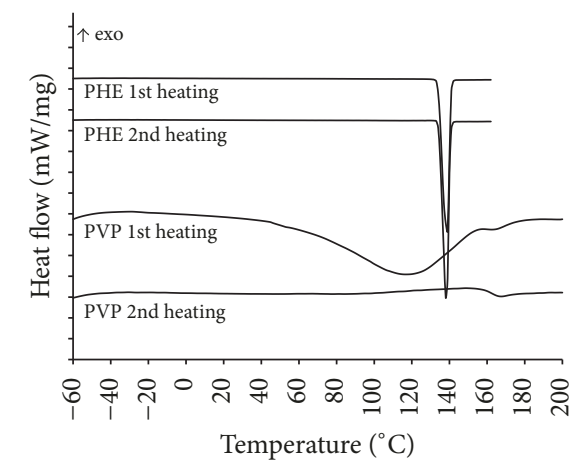

(b)

Figure 2: (a) Results of TG/DSC/MS analysis of PHE and PVP K29-32 in the dynamic argon atmosphere $75 \mathrm{ml} / \mathrm{min}$ in the temperature range $40-500^{\circ} \mathrm{C}$. Ion thermogram of $\mathrm{H}_{2} \mathrm{O}(\mathrm{m} / z=18)$ is shown. Heating rate is $5^{\circ} \mathrm{C} / \mathrm{min}$. (b) DSC curves of the initial samples of PVP K29-32 and $\mathrm{PHE}$ in the dynamic atmosphere of argon $150 \mathrm{ml} / \mathrm{min}$. Heating rate is $5^{\circ} \mathrm{C} / \mathrm{min}$.

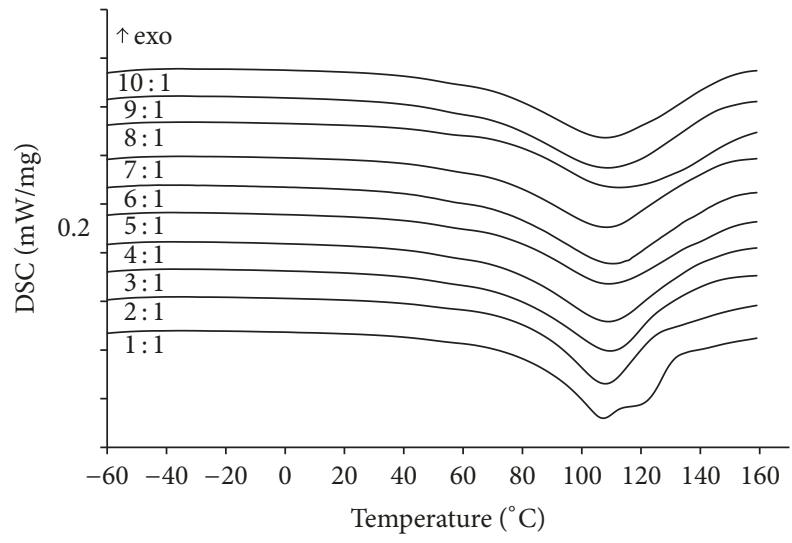

(a)

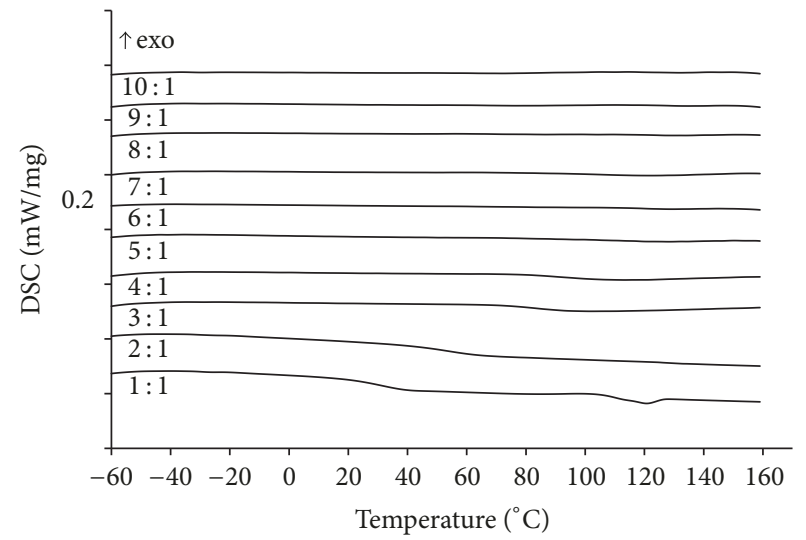

(b)

Figure 3: DSC curves of PVP K29-32/PHE mechanical mixtures of different compositions (1-10:1) in dynamic argon atmosphere $150 \mathrm{ml} / \mathrm{min}$ and temperature range $-60-160^{\circ} \mathrm{C}$. (a) First heating; (b) second heating. Heating rate is $5^{\circ} \mathrm{C} / \mathrm{min}$.

\section{Results and Discussion}

3.1. Results of Thermoanalysis of Individual Compounds and Their Physical Mixtures. The results of combined TG/DSC/ MS analysis of PHE and PVP K29-32 are presented in Figure 2(a). There is no observed mass loss for PHE in the temperature range $40-160^{\circ} \mathrm{C}$.

A thermal decomposition of PHE is observed above $180^{\circ} \mathrm{C}$; therefore low-temperature DSC measurements of composites were limited to the temperatures below $160^{\circ} \mathrm{C}$. A distinct endoeffect occurs between 130 and $175^{\circ} \mathrm{C}$ on the DSC curves, which corresponds to drug melting. Thermal effects on the DSC curve above $180^{\circ} \mathrm{C}$ are related to thermal decomposition of the drug. A mass loss (3.4\%) combined with endoeffect within $40-200^{\circ} \mathrm{C}$ is observed for polyvinylpyrrolidone K29-32; both are related to the elimination of water $(\mathrm{m} / z=$ 18). Decomposition of PVP K29-32 is observed above $350^{\circ} \mathrm{C}$.

Low-temperature differential scanning calorimetry was employed for more accurate analysis of thermal effects of phase transitions including low-temperature region. The results of DSC analysis of PHE and PVP K29-32 are presented in Figure 2(b).
Endoeffects of melting with onsets at $134.4^{\circ} \mathrm{C}$ and $134.1^{\circ} \mathrm{C}$ and enthalpies $188.8 \mathrm{~J} / \mathrm{g}$ and $188.7 \mathrm{~J} / \mathrm{g}$ for first and second heating, respectively, are observed on the heating curves of PHE (Figure 2(b)). Temperature and enthalpy values agree with previous measurements [45]. No additional effects in the studies temperature range are observed on DSC curves. An endoeffect related to the elimination of water is visible on the first heating DSC curve of polyvinylpyrrolidone K29-32 and a glass transition afterward. A glass transition at $T_{g}=163.0^{\circ} \mathrm{C}$ is more clear on the second heating.

Thermophysical properties of mechanical mixtures of PVP K29-32 with PHE with 1:1, 2:1, 3:1, 4:1, 5:1, 6:1, $7: 1,8: 1,9: 1$, and $10: 1$ compositions were studied using low-temperature DSC in the temperature range $-60-160^{\circ} \mathrm{C}$. Analysis results are presented in Figure 3.

On the first heating of physical mixtures of PVP K29-32 and PHE (Figure 3(a)) endoeffects related to the elimination of water are observed. The water content in the studied samples, determined using TG/DSC/MS analysis, is between 3.0 and $4.8 \%$. No other effects are observed for PVP K2932 : PHE 2-10:1 mixtures. In the same time, a shoulder of the endoeffect of PHE melting is found for the 1:1 mixture. This 


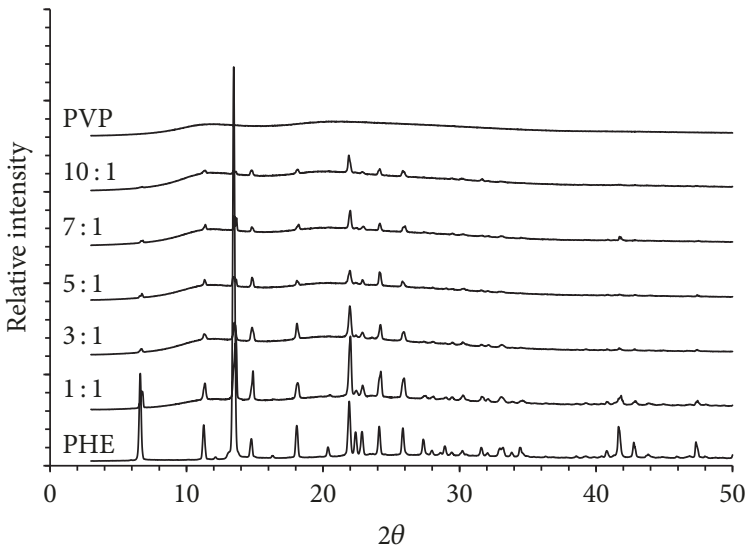

(a)

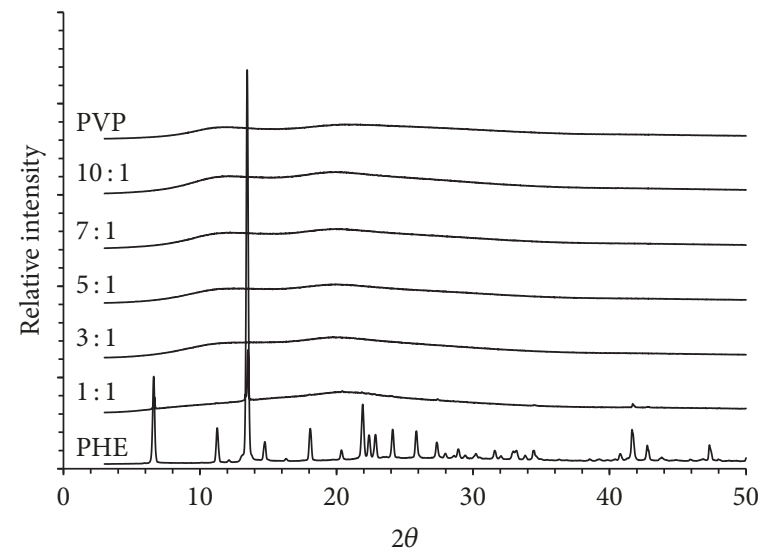

(b)

Figure 4: Powder X-ray diffractograms of PVP K29-32, PHE, their physical mixtures of different compositions (a), and same mixtures after melting (b).

fact supports the lack of crystal phase of PHE in composites with compositions $2-10: 1$.

On the second heating of studied PVP K29-32: PHE mixtures (Figure 3(b)) thermal effect of PHE melting is also observed in $1: 1$ mixture. Melting of PHE is not visible in other mixtures. Furthermore, for mixtures of 1-5:1 composition a glass transition of PVP K29-32 is clearly visible with $T_{g}$ $33.0^{\circ} \mathrm{C}(1: 1), 55.0^{\circ} \mathrm{C}(2: 1), 84.0^{\circ} \mathrm{C}(3: 1), 89.7^{\circ} \mathrm{C}(4: 1)$, and $98.5^{\circ} \mathrm{C}(5: 1)$. Such behavior evidences plasticizing effect of PHE and must be considered for the optimization of spray drying process as the temperature of drying must be at least $10^{\circ} \mathrm{C}$ below $T_{g}[54]$.

Therefore based on DSC data the optimal composition of PVP K29-32: PHE mixture is $5: 1$, because for this mixture no separate crystal phase of PHE was observed, glass transition of PVP K29-32 has a temperature well above spray drying process temperature, and the content of drug is maximal.

\subsection{PXRD of Initial Compounds and Their Physical Mixtures.}

Figure 4 demonstrates the results of powder X-ray diffractometry of the initial samples of polyvinylpyrrolidone K2932 , PHE, and their physical mixtures (Figure 4(a)) of $1: 1,3: 1$, $5: 1,7: 1$, and $10: 1$ composition (by weight) as well as same mixtures after melting (Figure 4(b)).

Reflections characteristic for PHE are visible in all diffractograms of physical mixtures. On the diffractograms of samples after melting, peaks of PHE are only observed in mixture with 1:1 PVP K29-32: PHE composition. A halo common for the amorphous phase is present in diffractograms for all other compositions, which correspond to the formation of solid dispersions. It must be noted that results of DSC and PXRD agree with each other. Therefore a combination of two different methods allows making a definite choice of optimal composition of PVP K29-32 and PHE for the formation of solid dispersion using spray drying process; this composition is $5: 1$ by weight.

3.3. Thermodynamics of Phenacetin Dissolution. Limiting solubility of PHE in water in presence of polyvinylpyrrolidone K29-32 was studied using UV-spectrophotometry.

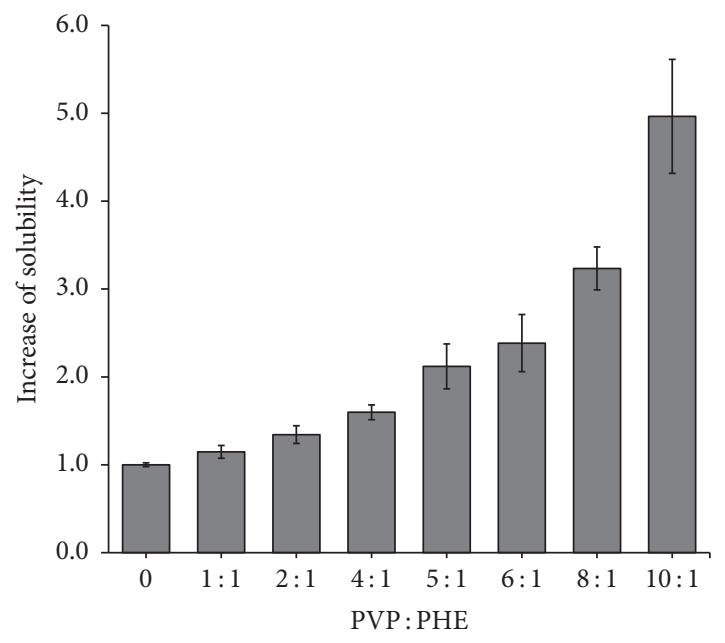

FIGURE 5: Results of UV spectrophotometric analysis of aqueous solutions of mixtures of PVP K29-32 and PHE at different component compositions. The optical density is measured at a wavelength of $245 \mathrm{~nm}$.

As visible from Figure 5 PHE concentration in solution increases upon the increase of polymer content. Compared to the solution of PHE without PVP K29-32 maximum solubility increase is 4.9 -fold.

The results obtained for Gibbs free energy of dissolution (Table 1) demonstrate the spontaneity of the solubilization process for polymer-drug compositions (5-10): 1. In general, the increase in solubility is directly associated with values of $\Delta_{S} G<0$, which is usually proportional to the increase in concentration of polymer, in such a way that the more negative the value of $\Delta_{S} G$, the better the solubilizing effect [17].

Therefore solution thermodynamics data for PHE in the presence of polyvinylpyrrolidone K29-32 are not contradicting previously determined optimal PVP K29-32: PHE composition of $5: 1$. Solubility increase for this composition is 2 times the value of pure PHE. 


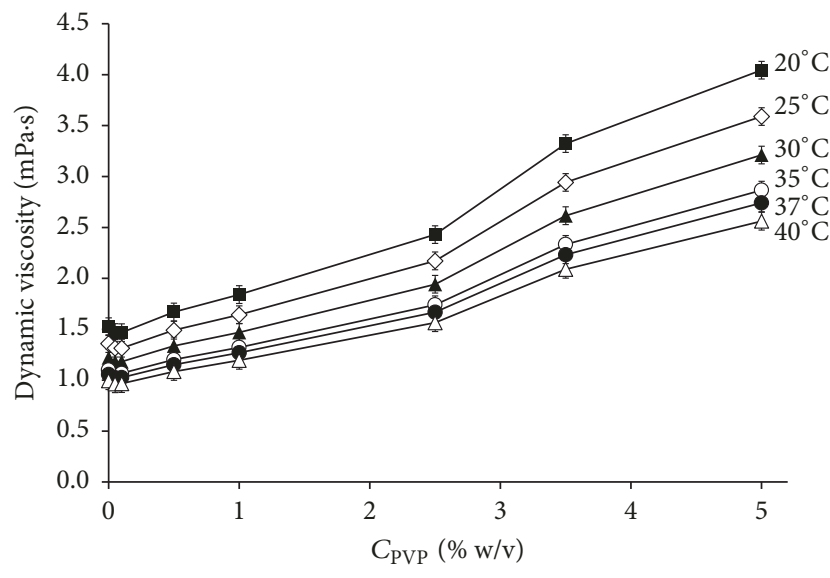

(a)

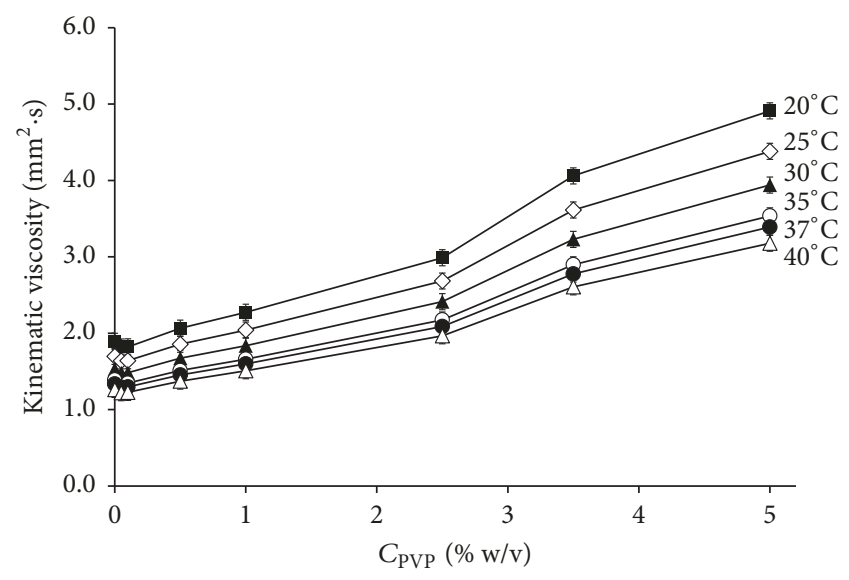

(b)

FIGURE 6: Dependence of dynamic (a) and kinematic (b) viscosity on PVP K29-32 concentration in ethanol at different temperatures.

TABLE 1: Values of Gibbs free energy of dissolution $\left(\Delta_{S} G\right)$ of PHE in water at different ratios of PVP K29-32 : PHE.

\begin{tabular}{lc}
\hline PVP :PHE ratio & $\Delta_{S} G, \mathrm{~J} / \mathrm{mol}$ \\
\hline $1: 1$ & $4757 \pm 301$ \\
$2: 1$ & $2651 \pm 200$ \\
$4: 1$ & $1277 \pm 67$ \\
$5: 1$ & $-281 \pm 34$ \\
$6: 1$ & $-806 \pm 110$ \\
$8: 1$ & $-1991 \pm 150$ \\
$10: 1$ & $-3413 \pm 446$ \\
\hline
\end{tabular}

3.4. Viscosity Study of PVP K29-32 Solution. Solution viscosity is one of the critical factors for a spray drying process and, together with surface tension, defines the size of the droplets formed $[55,56]$. Therefore, a study of the kinematic and dynamic viscosities of PVP K29-32 solutions in ethanol depending on polymer concentration was carried out.

As evident from Figure 6 increase of PVP K29-32 concentration up to $2.5 \% \mathrm{w} / \mathrm{v}$ causes an almost linear increase of solution viscosity at all temperatures studied. The magnitude of solubility increase as compared to pure ethanol is not higher than 1.6-fold. Further PVP K29-32 content increase in ethanol up to $3.5 \% \mathrm{w} / \mathrm{v}$ leads to a relatively sharp viscosity increase. Similar behavior was previously shown for PVP K29-32 solutions in water and alcohols $[57,58]$. Because of this for a spray drying process, a concentration of PVP K29$32,2.5 \% \mathrm{w} / \mathrm{v}$, was chosen.

3.5. Physicochemical Properties of Phenacetin Spray-Dried Solid Dispersion. Average product yields of spray drying were $47 \pm 2,60 \pm 2$, and $61 \pm 3 \%$ for particles, formed with 4.0, 5.5 , and $7.0 \mu \mathrm{m}$ hole size, respectively. Dried samples had the appearance of white powders and were analyzed using several physicochemical methods. Moreover, in a separate independent experiment, it was demonstrated that spray drying does not commence at PVP K29-32 concentration over $3.5 \%$ in solution, because of high solution viscosity. This

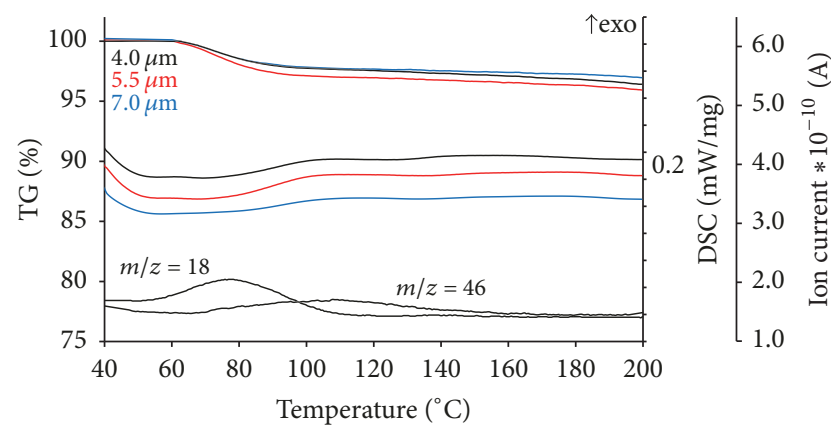

FIgURE 7: TG/DSC/MS results of microspherical particles formed by spray drying with three different spray caps $(4.0,5.5$, and $7.0 \mu \mathrm{m}$ hole size) in dynamic argon atmosphere $75 \mathrm{ml} / \mathrm{min}$. Heating rate is $5^{\circ} \mathrm{C} / \mathrm{min}$. Ion thermograms $\mathrm{m} / z=18$ and $\mathrm{m} / z=46$ correspond to water and ethanol, respectively (data is shown for particles formed by spray drying with spray caps $5.5 \mu \mathrm{m}$ hole size).

supports the choice of solution concentration made from viscosity measurements.

3.5.1. Solvent Content in Microparticles. Residual solvent content in microspherical particles was investigated using TG/DSC/MS. The results are presented in Figure 7. For all studied samples, the mass loss between 40 and $140^{\circ} \mathrm{C}$ is below $3.6 \%$. This loss of mass is related to water and ethanol elimination as evidenced by the ion thermograms for $m / z=18$ and $m / z=46$, respectively. The solvent loss is accompanied by the endoeffect on DSC curves. The majority of water is lost below $100^{\circ} \mathrm{C}$, which supports the lack of strong intermolecular interactions and is a prerequisite for good storage stability including high humidity conditions.

A presence of water in produced solid dispersions may be attributed to the hygroscopicity of the PVP polymers [59].

It must be noted that water constitutes the majority of the mass loss of samples, while ethanol is eliminated at temperatures above its boiling point; this points to the formation of relatively strong solvate complexes during spray 


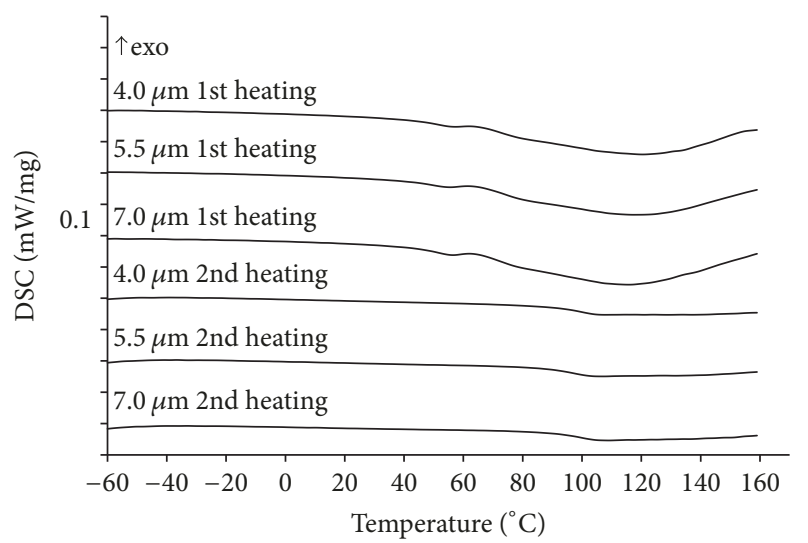

FIGURE 8: DSC curves of microspherical particles formed using spray drying process with three different spray caps $(4.0,5.5$, and $7.0 \mu \mathrm{m}$ hole size) in dynamic argon atmosphere $150 \mathrm{ml} / \mathrm{min}$. Heating rate is $5^{\circ} \mathrm{C} / \mathrm{min}$.

drying. However, the amount of ethanol bond is negligibly low.

Therefore, it can be concluded that spray drying parameters (inlet temperature and drying air flow) allow the formation of microparticles with relatively low residual solvent content.

3.5.2. Differential Scanning Calorimetry. Upon the first heating of microparticles endoeffects related to the loss of solvents are visible on DSC curves (Figure 8). No other effects are found. Polyvinylpyrrolidone K29-32 glass transitions at 99.7, 99.6, and $97.2^{\circ} \mathrm{C}$ for particles formed using $4.0,5.5$, and $7.0 \mu \mathrm{m}$ hole size, respectively, are present on DSC curves of second heating. This temperature is close to the glass transition observed upon second heating in a physical mixture PVP K29-32: PHE 5:1 $\left(98.5^{\circ} \mathrm{C}\right.$ ) (Figure 3(b)). This means that the drug content in microparticles is close to theoretical values.

Relatively high glass transition temperature promotes good storage stability at room temperature; the prolonged physical stability of amorphous materials is possible if storage temperature is at least $50^{\circ} \mathrm{C}$ below the glass transition [60].

A lack of endoeffects of PHE melting is an indirect evidence of the formation of solid dispersion during spray drying.

3.5.3. PXRD of Microparticles. No characteristic reflections of PHE are observed on powder diffractograms (Figure 9), which supports the lack of crystal phase in the particles and further supports earlier conclusion on the formation of solid dispersions during spray drying.

No crystal phase of PHE was found upon 4-month storage in ambient condition (Figure 9).

3.5.4. FTIR Spectroscopy of Microparticles. IR spectra of PHE and polyvinylpyrrolidone K29-32 powders, as well as microspherical particles produced by spray drying process with three different spray caps, are demonstrated in Figure 10. Spectra of all microspherical particles are visibly

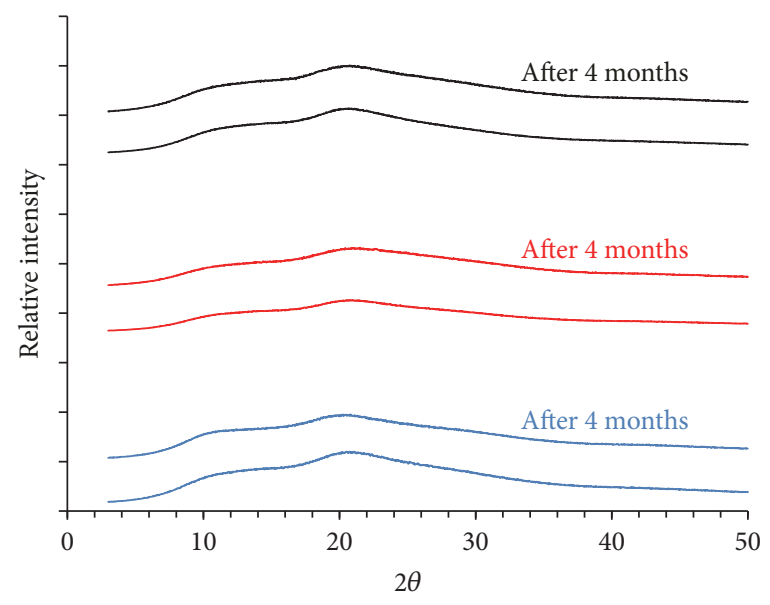

FIgure 9: Powder X-ray diffractograms of freshly generated microspherical particles prepared with three different spray caps $(4.0 \mu \mathrm{m}$ (black), $5.5 \mu \mathrm{m}$ (red), and $7.0 \mu \mathrm{m}$ (blue) hole size) and after 4-month storage in ambient conditions.

similar (Figure 10(a)), which supports the closeness of the prepared solid dispersions. PHE absorbance bands at 1646 and $1659 \mathrm{~cm}^{-1}$ correspond to free and $\mathrm{H}$-bonded $\mathrm{C}=\mathrm{O}$ groups in crystals [50].

A shoulder of the band related to the free $\mathrm{C}=\mathrm{O}$ PHE group is visible on the IR spectra of microspherical particles (Figure 10(b)), while no bonded carbonyl group signal $\left(1646 \mathrm{~cm}^{-1}\right)$ is present. This observation further supports the lack of PHE crystal phase growth during the spray drying process and solid dispersion formation with PVP K29-32, as in the latter PHE is present in amorphous condition and prevented from the H-bonding of the PHE-PHE type. Furthermore, a capacity of PVP K29-32 towards H-bonding with PHE can effectively prevent the crystallization $[61,62]$. The absence of chemical changes of the drug after spray drying is supported by the lack of changes in the position of the characteristic IR-bands of phenacetin between the initial substance and resultant microparticles [30].

3.5.5. Shape and Size Distribution of Microparticles. SEM images of microspherical particles formed using spray drying process with three different spray caps together with size distribution curves are presented in Figure 11.

Prepared particles have a spherical shape (Figures 11(a)-11(c)). Formation of spherical particles with no surface defects corresponds to a lack of external shell growth during the spray drying because of low concentration [40]. A lack of polymer shell also reflects the homogeneity of the solid dispersion and good affinity of PHE towards polyvinylpyrrolidone K29-32. It must be noted that a regular spherical shape together with the lack of agglomeration should promote good particle aerodynamics.

Distribution curves were plotted based on the data from 3801, 4238, and 2193 particles and were described using amplitude version of Gaussian peak function, probability density function of random variable whose logarithm is normally distributed, and Chesler-Cram peak function for spray 


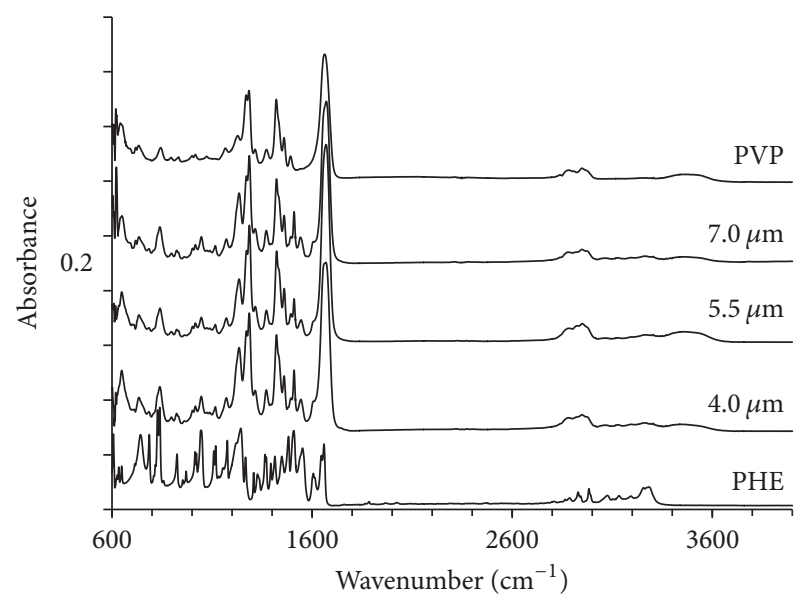

(a)

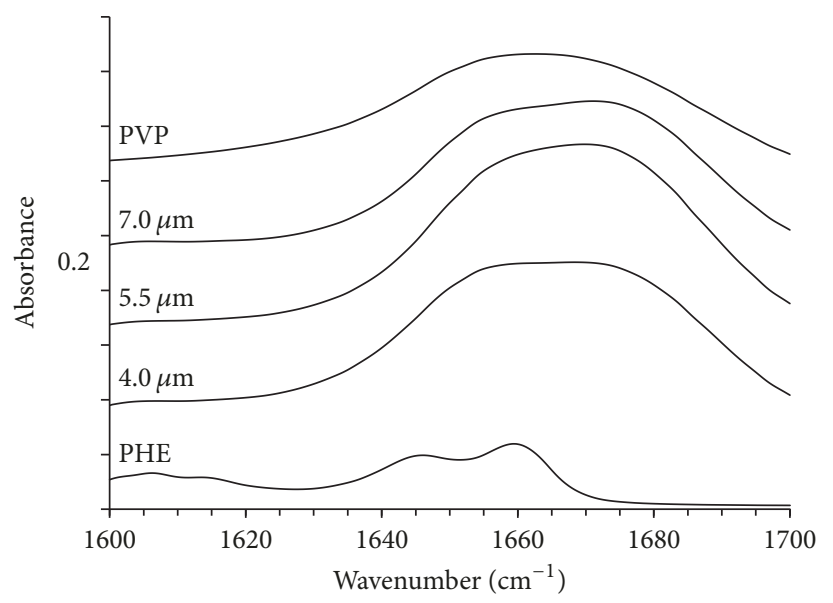

(b)

FIGURE 10: IR spectra of PVP K29-32, PHE, and microspherical particles formed using spray drying with three different spray caps (4.0, 5.5, and $7.0 \mu \mathrm{m}$ hole size) in the wavenumber range $600-4000 \mathrm{~cm}^{-1}$ (a) and $1600-1700 \mathrm{~cm}^{-1}$ (b).

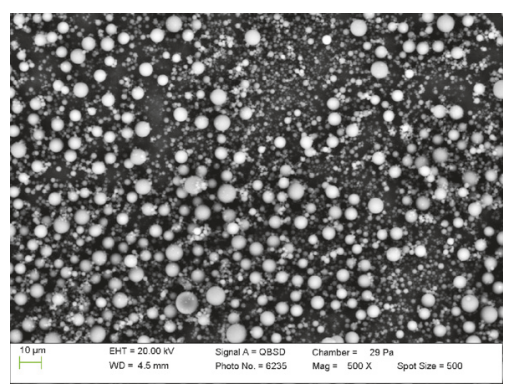

(a)

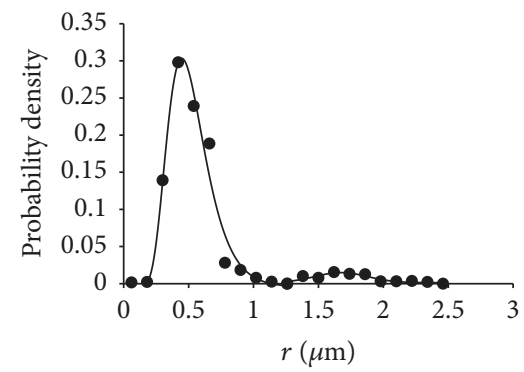

(d)

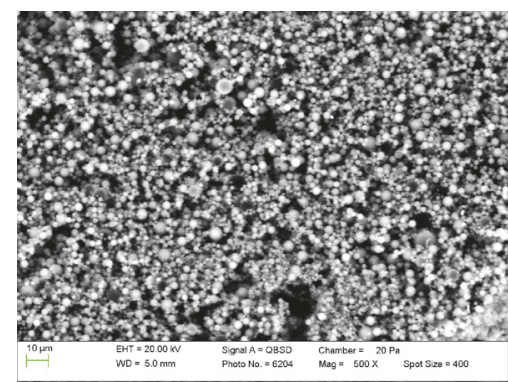

(b)

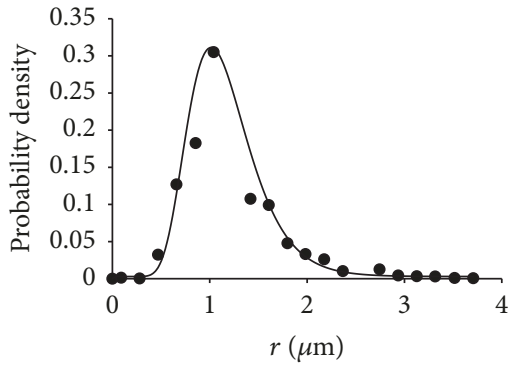

(e)

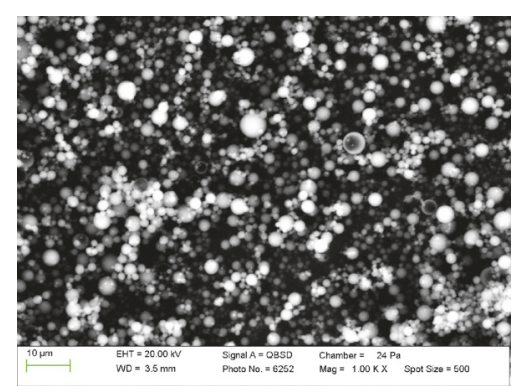

(c)

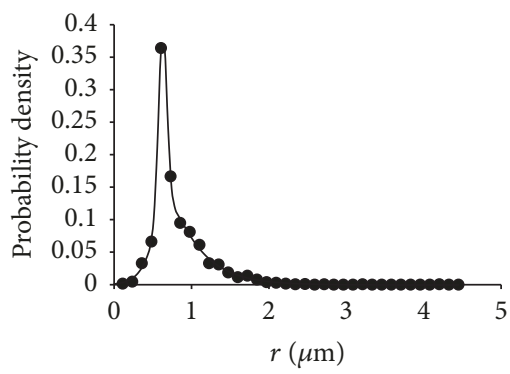

(f)

FIGURE 11: SEM images of PVP K29-32/PHE composites, formed using spray drying process with three different spray caps with $4.0 \mu \mathrm{m}$ (a), $5.5 \mu \mathrm{m}(\mathrm{b})$, and $7.0 \mu \mathrm{m}$ (c) hole size and size distribution curves calculated from these images for spray caps with $4.0 \mu \mathrm{m}(\mathrm{d}), 5.5 \mu \mathrm{m}(\mathrm{e})$, and $7.0 \mu \mathrm{m}(\mathrm{f})$ hole size.

caps with $4.0 \mu \mathrm{m}, 5.5 \mu \mathrm{m}$, and $7.0 \mu \mathrm{m}$ hole size, respectively (Figures 11(d)-11(f)).

Two maxima are present on size distribution curve of spray caps with $4.0 \mu \mathrm{m}$ hole size. This can be explained by the formation of bigger particles via agglomeration of droplets at the time of their generation, which reduces surface energy. A single peak is found on the size distribution curves of particles formed with spray caps of $5.5 \mu \mathrm{m}$ and $7.0 \mu \mathrm{m}$ hole size. Mean radii of particles and standard deviations (excluding points with less than 1 per 1000 occurrences) are presented in Table 2.
TABLE 2: Values of maxima (curve peaks) and corresponding standard deviations of the microparticles radius presented in Figure 11. Calculated aerodynamic radii are shown in brackets.

\begin{tabular}{lcc}
\hline Spray caps hole size & Peak $(\mu \mathrm{m})$ & Standard deviations $(\mu \mathrm{m})$ \\
\hline \multirow{2}{*}{4.0} & $0.42(0.48)$ & 0.31 \\
& $1.60(1.82)$ & 0.35 \\
5.5 & $1.04(1.19)$ & 1.01 \\
7.0 & $0.61(0.70)$ & 0.64 \\
\hline
\end{tabular}


As seen from Table 2 narrowest distribution is achieved in particles formed with spray caps of $4.0 \mu \mathrm{m}$ hole size. However this sample contains two types of particles; moreover, the bigger particles are above $3 \mu \mathrm{m}$ in diameter, which limits their applicability in an inhalation administration. A wide size distribution is observed for particles made using $5.5 \mu \mathrm{m}$ hole size, with a substantial contribution of sizes over $3 \mu \mathrm{m}$. Microspherical particles formed using spray caps with $7.0 \mu \mathrm{m}$ hole size have relatively narrow size distribution. A large number of particles are less than $3 \mu \mathrm{m}$ in diameter, which is the optimal condition for inhalation delivery. Smaller deviation from the mean value for the spray caps with $7.0 \mu \mathrm{m}$ hole size compared to $5.5 \mu \mathrm{m}$ hole size spray caps was demonstrated earlier [39]. The disproportion between particle sizes and the hole size can be attributed to the interplay of solution viscosity and the surface tension during droplet formation [55, 56]. Bigger droplets formed using spray caps with $7.0 \mu \mathrm{m}$ hole size have less of a tendency for aggregation. The values of aerodynamic radii of the particles, calculated using equations 3-28 from [63], are presented in the Table 2. The aerodynamic diameters of the particles formed using spray caps with $7.0 \mu \mathrm{m}$ hole size are in the range between 1.3 and $2.9 \mu \mathrm{m}$, which allow their application for inhalation delivery.

3.5.6. Drug Content. PHE content in the composite determined using UV-spectrophotometry was $18.7 \pm 1.8 \%, 17.0 \pm$ $2.7 \%$, and $18.0 \pm 1.3 \%$ for microspherical particles, produced by spray drying using spray caps with $4.0,5.5$, and $7.0 \mu \mathrm{m}$ hole size, respectively.

The percent drug content in solid dispersions was found to be excellent and was approximately close to the theoretical values $(16.7 \%)$. This proves that the spray drying method is suitable for the preparation of solid dispersions of PHE.

3.6. In Vitro Dissolution Study. Dissolution kinetics of the drug is one of the main factors considered for the development of the new drug delivery forms. Thereby the dissolution kinetics of PHE from the microspherical particles produced in the present study was investigated. Kinetic assays were performed at $\mathrm{pH}=6.86$, as it was earlier shown that pleural fluid of patients with some diseases has $\mathrm{pH}$ below $7[64,65]$.

As seen from kinetic curves presented in Figure 12 a polymer matrix increases the dissolution rate of PHE. Full dissolution of drug from the spherical particles is achieved in the first 10 minutes, while for pure PHE full dissolution was observed no earlier than after 90 minutes after the start of the experiment.

A study of dissolution kinetics shows that microspherical particles demonstrate fast dissolution rate, which permits their application in drug inhalation delivery systems. The rate of PHE dissolution is affected not only by the presence of polymer but also by the particle size.

\section{Conclusion}

Based on the DSC and PXRD data optimal ratio of PVP K29-32: PHE was established to be $5: 1$ by weight. No crystal phase of PHE is formed, glass transition temperature of the

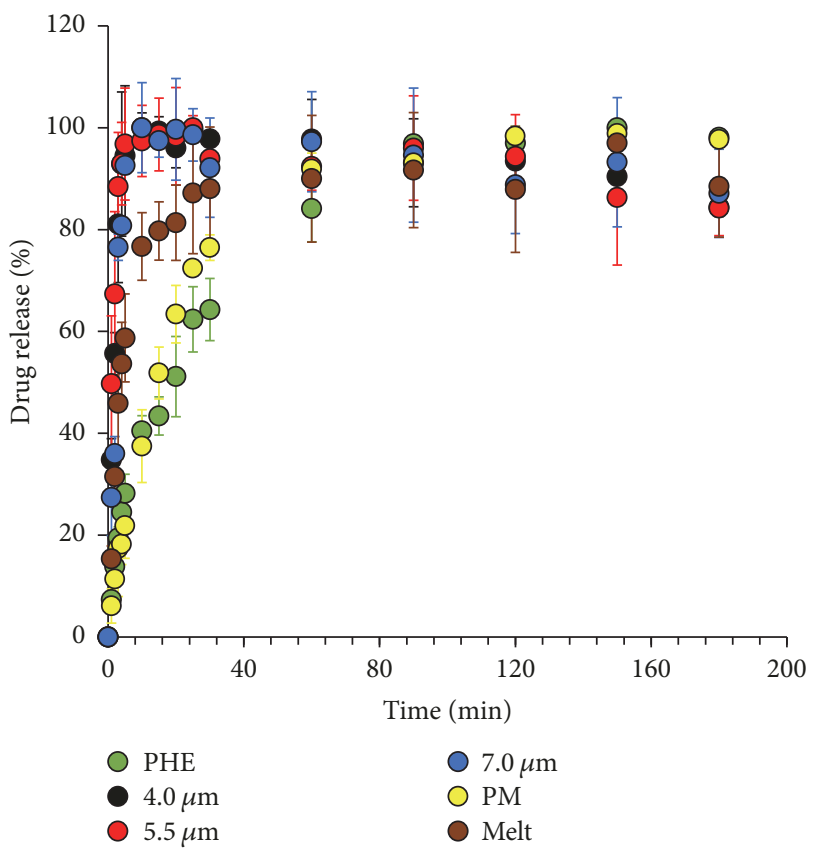

FIGURE 12: Dissolution profiles of crystalline PHE (green) and microspherical particles produced by spray drying using spray caps with $4.0 \mu \mathrm{m}$ (black), $5.5 \mu \mathrm{m}$ (red), and $7.0 \mu \mathrm{m}$ (blue) hole size, $1: 5$ physical mixture of PHE with PVP K29-32 (yellow), and 1:5 solid dispersion of PHE with PVP K29-32, formed by melting (brown) in a buffer solution, $\mathrm{pH}=6.86$.

polymer is well above spray drying condition, and the Gibbs energy of dissolution is negative for this composition. Based on the viscosity measurements of polyvinylpyrrolidone K2932 solution in ethanol, an optimal concentration of the former in the latter was found to be $2.5 \% \mathrm{w} / \mathrm{v}$.

Microspherical particles of solid dispersions of polyvinylpyrrolidone K29-32 with model hydrophobic drug, PHE produced using spray drying, were studied using several physicochemical methods: SEM, DSC, PXRD, and FTIR. It is found that the spray drying process parameters enable producing particles with relatively low solvent content, on which PHE stays in amorphous form for no less than 4 months. Particles prepared using spray caps with $7.0 \mu \mathrm{m}$ hole size have optimal size distribution for inhalation administration. The drug content in microparticles was found to be excellent and was approximately close to the theoretical values.

Measured dissolution kinetics of PHE evidence that dissolution rate of PHE from microspherical particles of solid dispersions allows their application as inhalation delivery systems with fast maximum concentration achievement time.

The results of the present study can be applied for the optimization of the spray drying process for the production of solid dispersion based on poorly soluble drugs with possible inhalation administration and enhanced bioavailability.

\section{Disclosure}

Earlier version of this work was presented at "1st International Seminar on Advanced Calorimetry." 


\section{Conflicts of Interest}

The authors declare that there are no conflicts of interest regarding the publication of this paper.

\section{Acknowledgments}

This work was supported by Ministry of Education and Science of Russian Federation Grant no. 14.Y26.31.0019.

\section{References}

[1] C. Loira-Pastoriza, J. Todoroff, and R. Vanbever, "Delivery strategies for sustained drug release in the lungs," Advanced Drug Delivery Reviews, vol. 75, pp. 81-91, 2014.

[2] J. S. Patton, C. S. Fishburn, and J. G. Weers, "The lungs as a portal of entry for systemic drug delivery," in Proceedings of the American Thoracic Society, vol. 1, pp. 338-344, 2004.

[3] W.-H. Lee, C.-Y. Loo, D. Traini, and P. M. Young, "Inhalation of nanoparticle-based drug for lung cancer treatment: Advantages and challenges," Asian Journal of Pharmaceutical Sciences, vol. 10, no. 6, pp. 481-489, 2015.

[4] J. S. Patton, "Mechanisms of macromolecule absorption by the lungs," Advanced Drug Delivery Reviews, vol. 19, no. 1, pp. 3-36, 1996.

[5] H. Chrystyn, "Is total particle dose more important than particle distribution?" Respiratory Medicine, vol. 91, pp. 17-19, 1997.

[6] A. F. Tena and P. C. Clarà, "Deposition of Inhaled Particles in the Lungs," Archivos de Bronconeumología (English Edition), vol. 48, no. 7, pp. 240-246, 2012.

[7] R. U. Agu, M. I. Ugwoke, M. Armand, R. Kinget, and N. Verbeke, "The lung as a route for systemic delivery of therapeutic proteins and peptides," Respiratory Research, vol. 2, no. 4, pp. 198-209, 2001.

[8] S. Rudt and R. H. Müller, "In vitro phagocytosis assay of nanoand microparticles by chemiluminescence. I. effect of analytical parameters, particle size and particle concentration," Journal of Controlled Release, vol. 22, no. 3, pp. 263-271, 1992.

[9] C. A. Lipinski, "Poor aqueous solubility - An industry wide problem in drug discovery," American Pharmaceutical Review, vol. 5, no. 3, pp. 82-85, 2002.

[10] Y. Kawabata, K. Wada, M. Nakatani, S. Yamada, and S. Onoue, "Formulation design for poorly water-soluble drugs based on biopharmaceutics classification system: basic approaches and practical applications," International Journal of Pharmaceutics, vol. 420, no. 1, pp. 1-10, 2011.

[11] S. Onoue, Y. Kojo, Y. Aoki, Y. Kawabata, Y. Yamauchi, and S. Yamada, "Physicochemical and Pharmacokinetic characterization of amorphous solid dispersion of tranilast with enhanced solubility in gastric fluid and improved oral bioavailability," Drug Metabolism and Pharmacokinetics, vol. 27, no. 4, pp. 379387, 2012.

[12] S. Baghel, H. Cathcart, and N. J. O’Reilly, "Polymeric amorphous solid dispersions: a review of amorphization, crystallization, stabilization, solid-state characterization, and aqueous solubilization of biopharmaceutical classification system class II drugs," Journal of Pharmaceutical Sciences, vol. 105, no. 9, pp. 2527-2544, 2016.

[13] V. Bühler, Polyvinylpyrrolidone excipients for pharmaceuticals. Povidone, crospovidone and copovidone, Springer-Verlag, Berlin, Germany, 2005.
[14] V. G. Kadajji and G. V. Betageri, "Water soluble polymers for pharmaceutical applications," Polymer, vol. 3, no. 4, pp. 19722009, 2011.

[15] A. Paradkar, A. A. Ambike, B. K. Jadhav, and K. R. Mahadik, "Characterization of curcumin-PVP solid dispersion obtained by spray drying," International Journal of Pharmaceutics, vol. 271, no. 1-2, pp. 281-286, 2004.

[16] A. A. Ambike, K. R. Mahadik, and A. Paradkar, "Spray-dried amorphous solid dispersions of simvastatin, a low Tg drug: in vitro and in vivo evaluations," Pharmaceutical Research, vol. 22, no. 6, pp. 990-998, 2005.

[17] R. P. Patel, D. J. Patel, D. B. Bhimani, and J. K. Patel, "Physicochemical characterization and dissolution study of solid dispersions of furosemide with polyethylene glycol 6000 and polyvinylpyrrolidone k30," Dissolution Technologies, vol.15, no. 3, pp. 17-25, 2008.

[18] A. Paudel, J. Van Humbeeck, and G. Van Den Mooter, “Theoretical and experimental investigation on the solid solubility and miscibility of naproxen in poly(vinylpyrrolidone)," Molecular Pharmaceutics, vol. 7, no. 4, pp. 1133-1148, 2010.

[19] F. Frizon, J. D. O. Eloy, C. M. Donaduzzi, M. L. Mitsui, and J. M. Marchetti, "Dissolution rate enhancement of loratadine in polyvinylpyrrolidone K-30 solid dispersions by solvent methods," Powder Technology, vol. 235, pp. 532-539, 2013.

[20] H. Saluja, A. Mehanna, R. Panicucci, and E. Atef, "Hydrogen bonding: Between strengthening the crystal packing and improving solubility of three haloperidol derivatives," Molecules, vol. 21, no. 6, article no. 719, 2016.

[21] C. L. Ng, S.-E. Lee, J.-K. Lee et al., "Solubilization and formulation of chrysosplenol $\mathrm{C}$ in solid dispersion with hydrophilic carriers," International Journal of Pharmaceutics, vol. 512, no. 1, pp. 314-321, 2016.

[22] X. Zhi, H. Fang, C. Bao et al., "The immunotoxicity of graphene oxides and the effect of PVP-coating," Biomaterials, vol. 34, no. 21, pp. 5254-5261, 2013.

[23] V. Escamilla-Rivera, M. Uribe-Ramírez, S. González-Pozos, O. Lozano, S. Lucas, and A. De Vizcaya-Ruiz, "Protein corona acts as a protective shield against Fe3O4-PEG inflammation and ROS-induced toxicity in human macrophages," Toxicology Letters, vol. 240, no. 1, pp. 172-184, 2016.

[24] P. R. Byron and J. S. Patton, "Drug delivery via the respiratory tract," Journal of Aerosol Medicine and Pulmonary Drug Delivery, vol. 7, no. 1, pp. 49-75, 1994.

[25] A. Hussain, J. J. Arnold, M. A. Khan, and F. Ahsan, "Absorption enhancers in pulmonary protein delivery," Journal of Controlled Release, vol. 94, no. 1, pp. 15-24, 2004.

[26] A. J. Singleton, "The use of Polyvinylpyrrolidone as a plasma volume expander in preventing or combating shock," Texas Reports on Biology and Medicine, vol. 11, pp. 138-143, 1953.

[27] B. V. Robinson, F. M. Sullivan, J. F. Borzelleca, and S. L. Schwartz, PVP - a critical review of the kinetics and toxicology of Polyvinylpyrrolidone (Povidone), Lewis Publishers, Chelsea, 1990.

[28] R. P. Kumar and A. Abraham, "PVP- coated naringenin nanoparticles for biomedical applications - In vivo toxicological evaluations," Chemico-Biological Interactions, vol. 257, pp. 110-118, 2016.

[29] C. Wu and J. W. McGinity, "Influence of ibuprofen as a solidstate plasticizer in Eudragit RS $30 \mathrm{D}$ on the physicochemical properties of coated beads.," AAPS PharmSciTech [electronic resource], vol. 2, no. 4, p. 24, 2001. 
[30] P. M. Oliveira, B. N. Matos, P. A. Pereira et al., "Microparticles prepared with $50-190 \mathrm{kDa}$ chitosan as promising non-toxic carriers for pulmonary delivery of isoniazid," Carbohydrate Polymers, vol. 174, pp. 421-431, 2017.

[31] J. Broadhead, S. K. Edmond Rouan, and C. T. Rhodes, "The spray drying of pharmaceuticals," Drug Development and Industrial Pharmacy, vol. 18, no. 11-12, pp. 1169-1206, 1992.

[32] Y.-C. Tseng, B. Linehan, K. J. Ng et al., "Cardiovascular safety pharmacology studies in dogs enabled for a poorly soluble molecule using spray-dried dispersion: Impact on lead selection," International Journal of Pharmaceutics, vol. 512, no. 1, pp. 137-146, 2016.

[33] M. Watanabe, M. Okada, Y. Kudo et al., "Differences in the effects of fibrous and particulate titanium dioxide on alveolar macrophages of Fischer 344 rats," Journal of Toxicology and Environmental Health, Part A. Current Issues, vol. 65, no. 15, pp. 1047-1060, 2002.

[34] A. Gharsallaoui, G. Roudaut, O. Chambin, A. Voilley, and R. Saurel, "Applications of spray-drying in microencapsulation of food ingredients: an overview," Food Research International, vol. 40, no. 9, pp. 1107-1121, 2007.

[35] D. A. Miller, D. Ellenberger, and M. Gil, "Spray-Drying Technology," in Formulating Poorly Water Soluble Drugs, vol. 22 of AAPS Advances in the Pharmaceutical Sciences Series, pp. 437525, Springer International Publishing, Cham, 2016.

[36] X. Li, N. Anton, C. Arpagaus, F. Belleteix, and T. F. Vandamme, "Nanoparticles by spray drying using innovative new technology: the Büchi Nano Spray Dryer B-90," Journal of Controlled Release, vol. 147, no. 2, pp. 304-310, 2010.

[37] S. H. Lee, D. Heng, W. K. Ng, H. K. Chan, and R. B. H. Tan, "Nano spray drying: a novel method for preparing protein nanoparticles for protein therapy," International Journal of Pharmaceutics, vol. 403, no. 1-2, pp. 192-200, 2011.

[38] A. B. D. Nandiyanto and K. Okuyama, "Progress in developing spray-drying methods for the production of controlled morphology particles: from the nanometer to submicrometer size ranges," Advanced Powder Technology, vol. 22, no. 1, pp. 1-19, 2011.

[39] M. Beck-Broichsitter, C. Schweiger, T. Schmehl, T. Gessler, W. Seeger, and T. Kissel, "Characterization of novel spray-dried polymeric particles for controlled pulmonary drug delivery," Journal of Controlled Release, vol. 158, no. 2, pp. 329-335, 2012.

[40] K. Jabłczyńska, M. Janczewska, A. Kulikowska, and T. R. Sosnowski, "Preparation and characterization of biocompatible polymer particles as potential nanocarriers for inhalation therapy," International Journal of Polymer Science, vol. 2015, Article ID 763020, 2015.

[41] T. Sou, M. P. McIntosh, L. M. Kaminskas, R. J. Prankerd, and D. A. V. Morton, "Designing a Multicomponent Spray-Dried Formulation Platform for Pulmonary Delivery of Biomacromolecules: The Effect of Polymers on the Formation of an Amorphous Matrix for Glassy State Stabilization of Biomacromolecules," Drying Technology, vol. 31, no. 13-14, pp. 1451-1458, 2013.

[42] T. Sou, L. M. Kaminskas, T.-H. Nguyen, R. Carlberg, M. P. McIntosh, and D. A. V. Morton, "The effect of amino acid excipients on morphology and solid-state properties of multicomponent spray-dried formulations for pulmonary delivery of biomacromolecules," European Journal of Pharmaceutics and Biopharmaceutics, vol. 83, no. 2, pp. 234-243, 2013.

[43] R. Bonfiglio, R. C. King, T. V. Olah, and K. Merkle, "The effects of sample preparation methods on the variability of the electrospray ionization response for model drug compounds," Rapid Communications in Mass Spectrometry, vol. 13, no. 12, pp. 1175-1185, 1999.

[44] N. Ono, F. Hirayama, H. Arima, K. Uekama, and J. H. Rytting, "Model analysis for oral absorption of a drug/cyclodextrin complex involving competitive inclusion complexes," Journal of Inclusion Phenomena and Macrocyclic Chemistry, vol. 44, no. 14, pp. 93-96, 2002.

[45] A. V. Gerasimov, M. A. Ziganshin, V. V. Gorbatchuk, and L. S. Usmanova, "Formation of solid dispersion of PEG-1000 with phenacetin according to differential scanning calorimetry," Der Pharma Chemica, vol. 5, no. 6, pp. 149-155, 2013.

[46] A. Galukhin, M. A. Khelkhal, A. Gerasimov et al., "Mncatalyzed oxidation of heavy oil in porous media: kinetics and some aspects of the mechanism," Energy \& Fuels, vol. 30, no. 9, pp. 7731-7737, 2016.

[47] A. V. Gerasimov, M. A. Ziganshin, and V. V. Gorbatchuk, "A calorimetric study of the formation of phenacetin solid dispersions with PEG-1400 and pluronic F127," World Applied Sciences Journal, vol. 24, no. 7, pp. 920-927, 2013.

[48] M. A. Ziganshin, A. A. Bikmukhametova, A. V. Gerasimov, V. V. Gorbatchuk, S. A. Ziganshina, and A. A. Bukharaev, "The effect of substrate and air humidity on morphology of films of L-leucyl-L-leucine dipeptide," Protection of Metals and Physical Chemistry of Surfaces, vol. 50, no. 1, pp. 49-54, 2014.

[49] M. A. Ziganshin, A. V. Gerasimov, S. A. Ziganshina et al., "Thermally induced diphenylalanine cyclization in solid phase," Journal of Thermal Analysis and Calorimetry, vol. 125, no. 2, pp. 905-912, 2016.

[50] A. Gerasimov, M. Varfolomeev, M. Ziganshin et al., “Thermodynamics of dissolution and infrared-spectroscopy of solid dispersions of phenacetin," Journal of Advanced Pharmaceutical Technology \& Research, vol. 7, no. 1, pp. 6-12, 2016.

[51] M. A. Varfolomeev, K. V. Zaitseva, I. T. Rakipov, B. N. Solomonov, and W. Marczak, "Speed of sound, density, and related thermodynamic excess properties of binary mixtures of butan-2-one with C1-C4 n-alkanols and chloroform," Journal of Chemical \& Engineering Data, vol. 59, no. 12, pp. 4118-4132, 2014.

[52] T. Jarunglumlert and K. Nakagawa, "Spray drying of casein aggregates loaded with $\beta$-carotene: influences of acidic conditions and storage time on surface structure and encapsulation efficiencies," Drying Technology, vol. 31, no. 13-14, pp. 1459-1465, 2013.

[53] U. Bhardwaj and D. J. Burgess, "A novel USP apparatus 4 based release testing method for dispersed systems," International Journal of Pharmaceutics, vol. 388, no. 1-2, pp. 287-294, 2010.

[54] K. Sollohub and K. Cal, "Spray drying technique: II. Current applications in pharmaceutical technology," Journal of Pharmaceutical Sciences, vol. 99, no. 2, pp. 587-597, 2010.

[55] A. W. Adamson, Physical Chemistry of Surfaces, John Wiley \& Sons, NJ, USA, 5th edition, 1990.

[56] G. Zhang, A. David, and T. S. Wiedmann, "Performance of the vibrating membrane aerosol generation device: Aeroneb micropump nebulizer ${ }^{\mathrm{TM}}$," Journal of Aerosol Medicine: Deposition, Clearance, and Effects in the Lung, vol. 20, no. 4, pp. 408416, 2007.

[57] H. Wen, K. R. Morris, and K. Park, "Study on the interactions between polyvinylpyrrolidone (PVP) and acetaminophen crystals: partial dissolution pattern change," Journal of Pharmaceutical Sciences, vol. 94, no. 10, pp. 2166-2174, 2005. 
[58] M. T. Zafarani-Moattar and Z. Khoshsima, "Measurement and correlation of density and viscosity of polyvinylpyrrolidone solutions in alcohols at different temperatures," The Journal of Chemical Thermodynamics, vol. 40, no. 11, pp. 1569-1574, 2008.

[59] J. C. Callahan, G. W. Cleary, M. Elefant, G. Kaplan, T. Kensler, and R. A. Nash, "Equilibrium moisture content of pharmaceutical excipients," Drug Development and Industrial Pharmacy, vol. 8, no. 3, pp. 355-369, 1982.

[60] B. C. Hancock, S. L. Shamblin, and G. Zografi, "Molecular mobility of amorphous pharmaceutical solids below their glass transition temperatures," Pharmaceutical Research, vol. 12, no. 6, pp. 799-806, 1995.

[61] Y. B. Kim, H. J. Song, and I. Y. Park, "Refinement of the structure of naproxen, (+)-6-methoxy- $\alpha$-methyl-2-naphthaleneacetic acid," Archives of Pharmacal Research, vol. 10, no. 4, pp. 232-238, 1987.

[62] X. Yuan, T.-X. Xiang, B. D. Anderson, and E. J. Munson, "Hydrogen bonding interactions in amorphous indomethacin and its amorphous solid dispersions with poly(vinylpyrrolidone) and poly(vinylpyrrolidone-co-vinyl acetate) studied using 13c solid-state NMR," Molecular Pharmaceutics, vol. 12, no. 12, pp. 4518-4528, 2015.

[63] W. C. Hinds, Aerosol Technology: Properties, Behavior, and Measurement of Airborne Particles, John Wiley \& Sons, NJ, USA, 2 nd edition, 1999.

[64] D. E. Potts, D. C. Levin, and S. A. Sahn, "Pleural fluid pH in parapneumonic effusions," CHEST, vol. 70, no. 3, pp. 328-331, 1976.

[65] M. C. Houston, "Pleural fluid pH: Diagnostic, therapeutic, and prognostic value," The American Journal of Surgery, vol. 154, no. 3, pp. 333-337, 1987. 

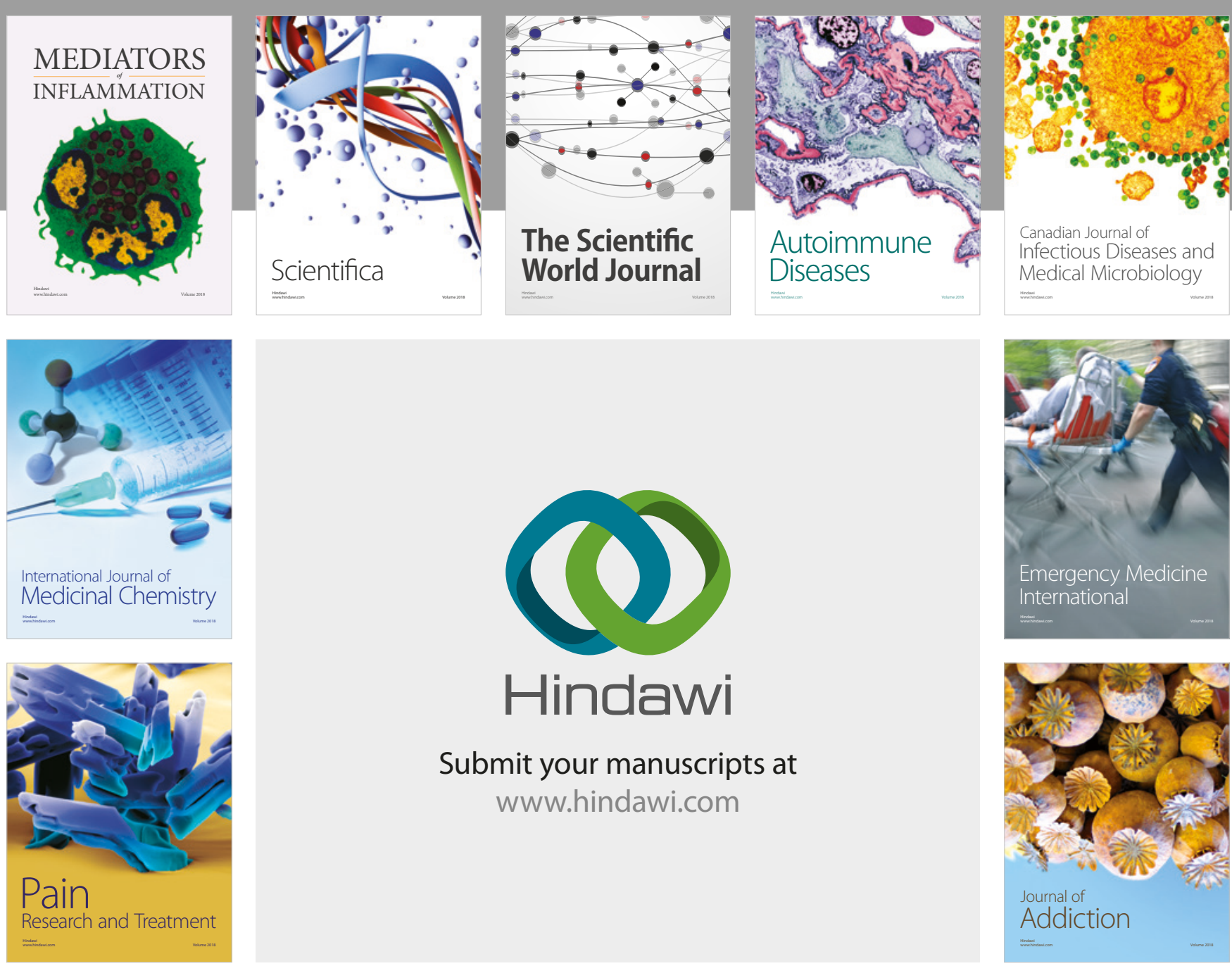

Canadian Journal of
Infectious Diseases and Medical Microbiology

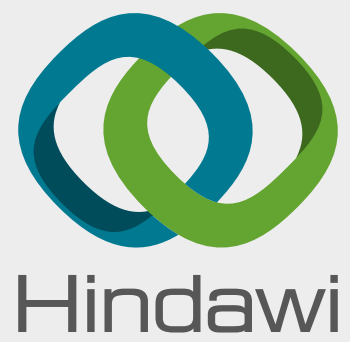

Submit your manuscripts at

www.hindawi.com
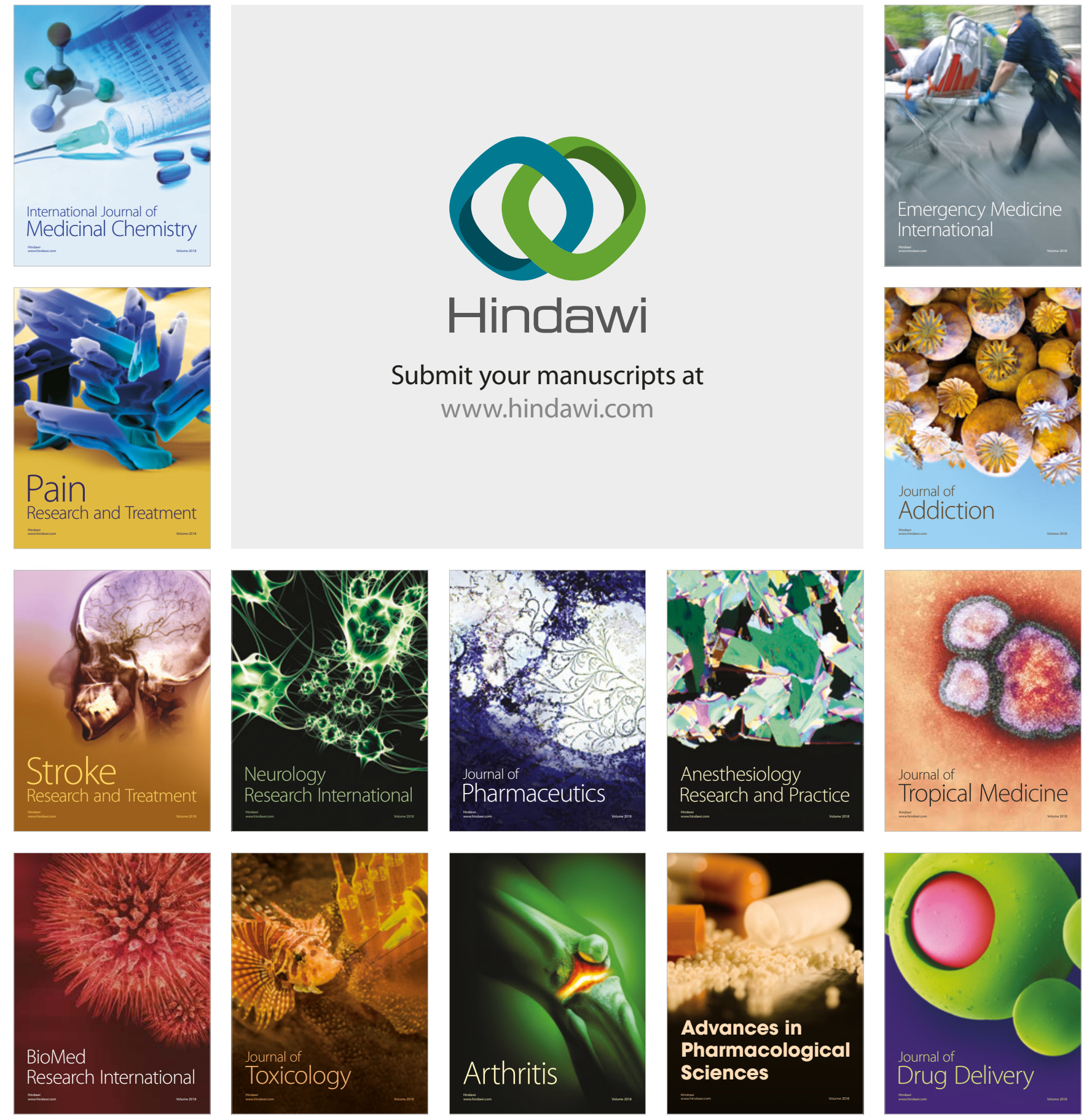